\title{
A Prospective Study of One-Muscle Surgery in 15-25 Prism Diopters Horizontal Comitant Strabismus in Adults
}

\section{Apatsa Lekskul \\ Wadakarn Wuthisiri \\ Nicha Jarupanich (ID)}

Department of Ophthalmology, Faculty of Medicine Ramathibodi Hospital, Mahidol University, Bangkok, Thailand
Correspondence: Nicha Jarupanich Department of Ophthalmology, Faculty of Medicine Ramathibodi Hospital, Mahidol University, 270 Rama VI Road, Ratchathewi, Bangkok, 10400, Thailand Tel +66 220I 2729

Fax +6622011516

Email N.jarupanich@gmail.com
Purpose: To prospectively evaluate the results of one-muscle surgery in 15-25 prism diopters (PD) horizontal comitant strabismus in adults.

Patients and Methods: 15-25 PD horizontal strabismus patients, comprising 25 exotropic (XT) patients and 11 esotropic (ET) patients, who underwent one-muscle recession by a single surgeon with a fixed surgical dosage were included in the study with a minimum follow-up of 3 months. The main outcome was a surgical success, which is defined as a residual deviation of $\angle 8 \mathrm{PD}$ at the last examination. Other parameters include postoperative lateral incomitance and patient satisfaction. Postoperative lateral incomitance indicated a difference in deviation of $>5$ PD between the primary position and lateral gaze, or duction limitation at any visit. Patient satisfaction regarding cosmetic and functional outcomes was assessed by using a 5-point Likert scale.

Results: Successful alignment was obtained in $19(76 \%)$ and $9(81.81 \%)$ XT and ET patients $(\mathrm{p}=1.00)$, with a median and interquartile range (IQR) of follow-up time of 3, 3-3 months and 3, 3-7 months, respectively. Postoperative lateral incomitance was observed in $8(32 \%)$ XT patients and in $1(9.09 \%)$ ET patient $(\mathrm{p}=0.22)$. One XT patient and one ET patient who developed incomitance reported diplopia, which disappeared 3 months after surgery. One XT patient reported diplopia while gazing towards the operated eye whilst one ET patient reported diplopia occasionally which was unrelated to gaze direction. Patient satisfaction was based on Likert scale scores with $4.12 \pm 0.97$ in XT patients and $4.73 \pm 0.65$ in ET patients $(\mathrm{p}=0.07)$.

Conclusion: One-muscle recession with a fixed surgical dosage was effective for treating small angle horizontal strabismus with a high rate of surgical success and patient satisfaction. Although postoperative lateral incomitance occurred, only a few patients developed symptomatic diplopia, which completely resolved 3 months after surgery.

Keywords: prospective, esotropia, exotropia, unilateral medial rectus recession, unilateral lateral rectus recession

\section{Introduction}

Strabismus is an ocular misalignment with an estimated pooled prevalence of 1.6$2.2 \%$ globally. ${ }^{1}$ This common eye condition has negative effects on visual-related quality of life as well as psychosocial implications; for example, social acceptance, self-image, securing employment, and interpersonal relationships. ${ }^{2-8}$ This study focused on the treatment for the two most common forms of strabismus, which are exotropia (XT) and esotropia (ET). 
The traditional treatment for both XT and ET is twomuscle strabismus surgery as either bilateral rectus muscle recession or combined unilateral rectus recession and antagonist rectus resection (URR). One-muscle recession has various theoretical advantages over two-muscle surgery, namely shorter operative time and less surgical complications. In addition, the muscles that are left untouched can be subject to further surgery. However, this procedure is controversial because of concerns regarding undercorrection and/or induced incomitance. Since one muscle surgery has been studied in only small to moderate angle strabismus and the majority of unsuccessful cases are undercorrection, ${ }^{9-34}$ it may not effective against large angle strabismus. A dose response relationship study suggested that one muscle recession can be used in XT or ET $<30$ prism diopters (PD). ${ }^{17}$ Several studies have shown that one-muscle surgery provides promising outcomes, specifically in small to moderate horizontal deviations, ${ }^{9-31}$ conversely, other studies reported a $<$ $60 \%$ success rate. ${ }^{32-34}$ Notably, most previous publications had retrospective designs. ${ }^{17-34}$ Owing to inconsistent surgical results, lack of standardized surgical dosage, possible risk of postoperative incomitance, and the limited number of prospective studies, in this study, we proposed a fixed amount of recession, addressed surgical outcomes, and evaluated postoperative incomitance prospectively in adults with 15-25 PD of horizontal deviation who underwent unilateral lateral rectus recession (ULR) for XT or unilateral medial rectus recession (UMR) for ET. This study specifically investigated patients with 15-25 PD deviation and did not cover those with the larger angle of deviation.

\section{Patients and Methods}

This study was approved by the Institutional Review Board of the Faculty of Medicine, Ramathibodi Hospital, Mahidol University (approval number: MURA2020/41) and was conducted according to the tenets of the Declaration of Helsinki. Informed consent was obtained from each patient who was eligible for the study and who agreed to undergo either UMR or ULR.

We recruited all consecutive patients with ET or XT of 15-25 PD who underwent unilateral horizontal muscle recession performed by the author $\mathrm{AL}$, a board-certified pediatric and strabismus ophthalmologist at Ramathibodi Hospital, Mahidol University from 5 March 2020 to 4 March 2021. The inclusion criteria were as follows: 1) being at least 18 years of age; 2) having comitant deviation; and 3) having a difference in deviation at 6 meters and 0.33 meters of $<5 \mathrm{PD}$. We excluded patients with restrictive strabismus, paralytic strabismus, previous extraocular muscle surgery, or A or V pattern.

\section{Preoperative Examination}

All patients received comprehensive ophthalmic evaluation including visual acuity (VA), slit-lamp biomicroscopy, ocular motility, and orthoptic examinations by authors AL or NJ. Orthoptic examination comprised of the coveruncover test and alternate prism cover test using a plastic prism placed in the patients' frontal plane while wearing their best refractive correction. Measurements were taken in primary, right, and left gazes at 6 meters and at 0.33 meters. The lateral gaze was estimated at 30 degrees from the primary position. In patients with exodeviation, orthoptic examination was performed after monocular patching for at least 30 minutes to eliminate fusional convergence and to reveal maximal deviation. ${ }^{35}$ The Krimsky light reflex test was used in patients who were unable to perform target fixation. The purpose and procedures in the study were informed to all patients.

\section{Surgical Dosage}

The surgical dosage for recession according to maximal deviation either at distant or near fixation within 1 week prior to the surgery and related specifically with the degree of deviation are shown in Table 1 . These numbers were modified from the standard formula for bilateral recession. In our preliminary (unpublished) study, we used the amount of bilateral recession of double the patients' deviation to recess one muscle. For example, for a patient with XT 15 PD, we doubled the deviation to 30 PD. According to the standard formula, the amount of bilateral recession for $30 \mathrm{PD}$ is $7 \mathrm{~mm}$. Therefore, a patient with XT $15 \mathrm{PD}$ was treated by using $7 \mathrm{~mm}$ unilateral lateral rectus recession. This formulation resulted in a high rate of undercorrection. To mitigate the undercorrection, we added 1 millimeter to the matched amount of bilateral recession to double the patients' deviation. Based on the previous example, for instance, the unilateral lateral rectus recession in patient with XT 15 PD would be performed using $8 \mathrm{~mm}$ instead of $7 \mathrm{~mm}$.

\section{Surgical Procedure}

All operations were performed by a single surgeon (AL). Exotropic patients and esotropic patients underwent ULR and UMR, respectively. The anesthesia and the surgical side were chosen, as appropriate, by the surgeon. If the patient had unequal visual function between eyes, the worst 
Table I Standard Formula for Bilateral Recession and Surgical Dosage for Unilateral Recession in This Study

\begin{tabular}{|l|c|c|c|c|}
\hline \multirow{2}{*}{} & \multicolumn{2}{|c|}{ Exotropia } & \multicolumn{2}{c|}{ Esotropia } \\
\cline { 2 - 5 } & $\begin{array}{c}\text { Standard Formula for } \\
\text { BLR }\end{array}$ & $\begin{array}{c}\text { Amount of ULR in This } \\
\text { Study }\end{array}$ & $\begin{array}{c}\text { Standard Formula for } \\
\text { BMR }\end{array}$ & $\begin{array}{c}\text { Amount of UMR in This } \\
\text { Study }\end{array}$ \\
\hline I5 PD & $4.0 \mathrm{~mm}$ & $8.0 \mathrm{~mm}$ & $3.0 \mathrm{~mm}$ & $5.5 \mathrm{~mm}$ \\
$20 \mathrm{PD}$ & $5.0 \mathrm{~mm}$ & $9.0 \mathrm{~mm}$ & $3.5 \mathrm{~mm}$ & $6.5 \mathrm{~mm}$ \\
$25 \mathrm{PD}$ & $6.0 \mathrm{~mm}$ & $10.0 \mathrm{~mm}$ & $4.0 \mathrm{~mm}$ & $7.0 \mathrm{~mm}$ \\
$30 \mathrm{PD}$ & $7.0 \mathrm{~mm}$ & & $4.5 \mathrm{~mm}$ & \\
$40 \mathrm{PD}$ & $8.0 \mathrm{~mm}$ & & $5.5 \mathrm{~mm}$ & \\
$50 \mathrm{PD}$ & $9.0 \mathrm{~mm}$ & & $6.0 \mathrm{~mm}$ & \\
\hline
\end{tabular}

Abbreviations: PD, prism diopter; BLR, bilateral lateral rectus recession; ULR, unilateral lateral rectus recession; BMR, bilateral medial rectus recession; UMR, unilateral medial rectus recession; $\mathrm{mm}$, millimeters.

eye was selected for surgery. The horizontal rectus muscle was exposed by a fornix incision and was then tied with 6-0 polyglycolic acid or 6-0 polyglactin suture with double-arm spatula needles. The amount of recession was measured from just posterior to the original tendon insertion using calipers. This delicate measurement was taken from neither the site anterior to the original tendon insertion nor on the original tendon insertion, but was taken from the site adjacently posterior to the original tendon insertion. The muscle was disinserted and reattached by standard scleral fixation at a marked position without hang-back or adjustable sutures. The conjunctiva was then closed with $8-0$ polyglactin interrupted sutures. These steps were performed in the same manner on all patients.

\section{Postoperative Evaluation}

Postoperatively, patients were followed up after 2 weeks, 3 months and 6 months and received the same orthoptic and ocular motility examinations which were done during the preoperative period. All examinations were performed by either author AL or NJ.

A successful result was defined as having a residual deviation of $<8 \mathrm{PD}$ in the primary position for both distance and near fixations at the final examination at least 3 months after surgery. Surgically-induced lateral incomitance was defined as a difference in deviation between the primary position and lateral gaze of $>5 \mathrm{PD}$ or any adduction or abduction deficit at any visit. In addition, we evaluated patient satisfaction using a 5 point-Likert scale. Patients were asked to rate their level of agreement with the sentence, "I am satisfied with the cosmetic and functional outcomes resulting from the one-muscle strabismus surgery." (1, strongly disagree; 2 , disagree; 3 , neither agree nor disagree; 4 , agree; 5 , strongly agree).

\section{Statistical Analysis}

Categorical data and numerical data with normal distribution were presented by percentage and mean \pm standard deviation (SD), respectively. Non-normally distributed numerical data was reported as median and interquartile range (IQR). To compare the differences between groups, the chi-square test or the Fisher exact test was applied for categorical data while Mann-Whitney $U$-test or $t$-test was used for numerical data. Statistical analysis was performed using Stata version 17 statistical software. P value $<0.05$ was considered as statistically significant.

\section{Results}

A total of 36 consecutive patients were recruited in this study, consisting of 25 exotropic patients and 11 esotropic patients, with a median (IQR) postoperative follow-up of 3 , 3-3 months (range, 3-10 months) and 3, 3-7 months (range, 3-12 months), respectively. Patient characteristics are presented in Table 2. The patients' average age at the time of surgery was $32.16 \pm 10.18$ years in the exotropic group and $35 \pm 13.25$ years in the esotropic group. There were 21 (84\%) exotropic female patients and $10(90 \%)$ esotropic female patients. The mean $( \pm \mathrm{SD})$ preoperative deviation was $20.04 \pm 4.29$ PD (range, 14-25 PD) at distant fixation and $19.68 \pm 4.35$ PD (range, 14-25 PD) at near fixation in XT group and $21 \pm 4.27 \mathrm{PD}$ (range, 14-25 PD) at both distant and near fixation in ET group. The age $(p=0.49)$, sex $(p=1.00)$, follow up time $(p=1.00)$, and preoperative deviation at distant fixation $(p=0.54)$ and at near fixation ( $p$ $=0.40$ ) were comparable in patients with XT and ET. The patients' visual acuity ranged from $20 / 20$ to no light perception, with 66 of 72 eyes (91.67\%) having better than 20/200 VA. The patients were divided into three subgroups according to the degree of maximal deviation at the primary 
Table 2 Patient Characteristics

\begin{tabular}{|c|c|c|c|c|}
\hline & & Exotropia $(n=25)$ & Esotropia $(n=1 I)$ & p-value \\
\hline Age (year; mean $\pm S D)$ & & $32.16 \pm 10.18$ & $35 \pm 13.25$ & 0.49 \\
\hline Female (n, \%) & & 21,84 & 10,90 & 1.00 \\
\hline Follow up time (month; median, IQR) & & $3,3-3$ & $3,3-7$ & 1.00 \\
\hline Deviation (PD; mean $\pm \mathrm{SD}$ ) & $\begin{array}{l}\text { Distant } \\
\text { Near }\end{array}$ & $\begin{array}{l}20.04 \pm 4.29 \\
19.68 \pm 4.35\end{array}$ & $\begin{array}{l}21 \pm 4.27 \\
21 \pm 4.27\end{array}$ & $\begin{array}{l}0.54 \\
0.40\end{array}$ \\
\hline Groups classified by amount of deviation ( $\mathrm{n}, \%)$ & $\begin{array}{l}15 \text { PD } \\
20 \text { PD } \\
25 \text { PD }\end{array}$ & $\begin{array}{l}8,32 \\
8,32 \\
9,36\end{array}$ & $\begin{array}{l}3,27.27 \\
3,27.27 \\
5,45.45\end{array}$ & 1.00 \\
\hline
\end{tabular}

Abbreviations: SD, standard deviation; IQR, interquartile range; PD, prism diopter.

position: $15 \mathrm{PD}$ (8 XT patients, 3 ET patients), $20 \mathrm{PD}$ (8 XT patients, 3 ET patients), and 25 PD (9 XT patients, 5 ET patients). In subgroups categorized by type of strabismus, XT patients comprised of 6 constant XT patients, 15 intermittent XT patients and 4 sensory XT patients while ET patients included 9 nonaccommodative ET patients and 2 sensory ET patients. All of the patients had full range of duction and version and equal deviation between the primary position and lateral gaze before surgery. All operations were performed under local anesthesia by inferotemporal peribulbar block with 4-6 $\mathrm{mL}$ of $1: 1$ mixture of $0.5 \%$ bupivacaine and $2 \%$ lidocaine. Hyaluronidase $1 \mathrm{IU} / \mathrm{mL}$ was added in the mixture to improve the quality of the anesthesia.

The results comparing the exotropic group and esotropic group are summarized in Table 3. The median (IQR) angle of deviation in the primary position 2 weeks after surgery were as follows: exodeviation at distance: 0, 0-8 PD (range, 0-14 PD) and near: 0, 0-6 PD (range, 0-12 PD) in the ULR group and esodeviation at distance: $0,0-0 \mathrm{PD}$ (range $0-8$ PD) and near: $0,0-4$ PD (range 0-8 PD) in the UMR group. On the last follow up visit, the mean angle of deviation in the primary position change to exodeviation at distance: 0 , 0-4 PD (range, 0-14 PD) and near: 0, 0-0 PD (range, 0-10
PD) in the ULR group, and esodeviation at distance: 0, 0-4 PD (range 0-12 PD) and near: 0, 0-6 PD (range, 0-12 PD) in the UMR group. The deviations during the early postoperative period at both fixations and the deviations of the last follow up visit at both fixations were comparable between XT and ET group with p-value as presented in Table 3. On the final visit, 28 (77.77\%) patients had achieved successful results, which was defined as residual deviation for both distance and near fixation of $<8$ PD. Nineteen (76\%) patients in the ULR group and $9(81.81 \%)$ patients in the UMR group achieved successful alignment. The difference in success rate between ULR group and UMR group was not statistically significant $(p=1.00)$. In the ULR subgroups divided by degree of deviation, 6 (75\%) of XT 15 PD patients, 6 (75\%) of XT 20 PD patients, 7 (77.78\%) of XT 25 PD patients achieved successful alignment $(\mathrm{p}=0.99)$. In ULR subgroups divided by type of XT, 4 $(66.66 \%)$ of constant XT patients, $12(80 \%)$ of intermittent XT patients, and $3(75 \%)$ of sensory XT patients met the criteria for success $(p=0.82)$. In the UMR subgroups categorized by amount of deviation, $3(100 \%)$ of ET 15 PD patients, 3 (100\%) of ET 20 PD patients, $3(60 \%)$ of ET 25 PD patients resulted in successful alignment $(p=0.46)$.

Table 3 Results Comparing Between Exotropic Group and Esotropic Group

\begin{tabular}{|c|c|c|c|c|c|c|c|}
\hline & \multicolumn{2}{|c|}{$\begin{array}{c}\text { Deviation at Postoperative } 2 \\
\text { Weeks (PD; Median, IQR) }\end{array}$} & \multicolumn{2}{|c|}{$\begin{array}{l}\text { Deviation at Postoperative } \\
\text { Last Visit (PD; Median, IQR) }\end{array}$} & \multirow{2}{*}{$\begin{array}{c}\text { Successful } \\
\text { Alignment } \\
(\mathrm{n}, \%)\end{array}$} & \multirow[t]{2}{*}{$\begin{array}{l}\text { Postoperative } \\
\text { LI (n, \%) }\end{array}$} & \multirow{2}{*}{$\begin{array}{c}\text { PS by the } 5 \\
\text { Point-Likert } \\
\text { Scale } \\
\text { (Mean } \pm \text { SD) }\end{array}$} \\
\hline & Distant & Near & Distant & Near & & & \\
\hline$X T(n=25)$ & $0,0-8$ & $0,0-6$ & $0,0-4$ & $0,0-0$ & 19,76 & 8,32 & $4.12 \pm 0.97$ \\
\hline ET $(n=11)$ & $0,0-0$ & $0,0-4$ & $0,0-4$ & $0,0-6$ & $9,81.81$ & I, 9.09 & $4.73 \pm 0.65$ \\
\hline $\mathrm{p}$-value & 0.22 & 0.95 & 0.72 & 0.51 & 1.00 & 0.22 & 0.07 \\
\hline
\end{tabular}

Abbreviations: PD, prism diopter; IQR, interquartile range; SD, standard deviation; LI, lateral incomitance; PS, patient satisfaction. 
In the UMR subgroups assorted by type of ET, 7 (77.78\%) of nonaccommodative ET patients, and $2(100 \%)$ of sensory ET patients reached successful results $(\mathrm{p}=1.00)$. The success rate between subgroups either categorized by degree of deviation or types of strabismus were comparable. Details on these subgroups are presented in Table 4 for XT group and Table 5 for ET group. There were no patients who were overcorrected in the early postoperative period and at the last examination. Eight patients who did not meet the requirement for success were undercorrected.

Postoperative lateral incomitance was noted in $8(32 \%)$ of the ULR patients, namely 2 patients with $8 \mathrm{~mm}$ of recession, 3 patients with $9 \mathrm{~mm}$ of recession, and 3 patients with $10 \mathrm{~mm}$ of recession. Of 8 ULR patients with lateral incomitance, there were 1 constant XT patient, 5 intermittent XT patients and 2 sensory XT patients. No ULR patients had a difference in deviation exceeding 5 PD between the primary position and lateral gaze. Abduction limitation was noted in all of the lateral incomitant ULR patients; however, all patients were able to abduct to more than $90 \%$ subjectively compared with the contralateral unoperated eye. All incomitance following
ULR occurred in the early postoperative period and persisted throughout the follow-up. An intermittent XT patient with $9 \mathrm{~mm}$ ULR reported diplopia when gazing toward the operated eye in the early postoperative period, which improved after 3 months after surgery. Lateral incomitance was observed in one patient in the UMR group in the early postoperative period, which resolved within 3 months after the surgery. This patient had nonaccommodative ET of 25 PD and underwent 7-mm right medial rectus recession. Esodeviation of $6 \mathrm{PD}$ was observed on the right gaze while orthophoria was ensured at primary position, and on the left gaze with distance fixation. Orthoptic examination at near fixation revealed orthophoria in the primary position and on both lateral gazes. The ocular motility test revealed full duction and version. The patient reported occasional diplopia in the early postoperative period that was not related to gaze and did not significantly affect her quality of life. Although the rate of lateral incomitance following ULR was greater than following UMR, the difference was not statistically significant $(p=0.22)$. The analysis of subgroups divided by either the amount of deviation or type of strabismus did not

Table 4 Surgical Outcomes for Subgroups of Exotropic Patients

\begin{tabular}{|c|c|c|c|c|c|c|c|c|c|}
\hline & & \multicolumn{3}{|c|}{ Successful Alignment } & \multicolumn{3}{|c|}{ Postoperative LI } & \multicolumn{2}{|c|}{$\begin{array}{l}\text { PS by the } 5 \text { Point- } \\
\text { Likert Scale }\end{array}$} \\
\hline & & $\begin{array}{c}\text { Success } \\
\text { (n) }\end{array}$ & $\begin{array}{c}\text { Failure } \\
\text { (n) }\end{array}$ & p-value & $\begin{array}{c}\text { Cases } \\
(n)\end{array}$ & $\begin{array}{c}\text { Noncases } \\
\text { (n) }\end{array}$ & p-value & Mean \pm SD & p-value \\
\hline $\begin{array}{l}\text { Subgroups by } \\
\text { amount of deviation }\end{array}$ & $\begin{array}{l}\text { XT I5 PD } \\
\text { XT } 20 \text { PD } \\
\text { XT } 25 \text { PD }\end{array}$ & $\begin{array}{l}6 \\
6 \\
7\end{array}$ & $\begin{array}{l}2 \\
2 \\
2\end{array}$ & 0.99 & $\begin{array}{l}2 \\
3 \\
3\end{array}$ & $\begin{array}{l}6 \\
5 \\
6\end{array}$ & 1.00 & $\begin{array}{c}4.38 \pm 1.19 \\
4 \pm 0.76 \\
4 \pm 1\end{array}$ & 0.69 \\
\hline $\begin{array}{l}\text { Subgroups by type of } \\
\text { XT }\end{array}$ & $\begin{array}{l}\text { Constant } X T \\
\text { Intermittent } X T \\
\text { Sensory } X T\end{array}$ & $\begin{array}{c}4 \\
12 \\
3\end{array}$ & $\begin{array}{l}2 \\
3 \\
1\end{array}$ & 0.82 & $\begin{array}{l}1 \\
5 \\
2\end{array}$ & $\begin{array}{c}5 \\
10 \\
2\end{array}$ & 0.51 & $\begin{array}{c}4.5 \pm 0.55 \\
4.06 \pm 0.96 \\
3.75 \pm 1.5\end{array}$ & 0.48 \\
\hline
\end{tabular}

Abbreviations: XT, exotropia; PD, prism diopter; SD, standard deviation; LI, lateral incomitance; PS, patient satisfaction.

Table 5 Surgical Outcomes for Subgroups of Esotropic Patients

\begin{tabular}{|c|c|c|c|c|c|c|c|c|c|}
\hline & & \multicolumn{3}{|c|}{ Successful Alignment } & \multicolumn{3}{|c|}{ Postoperative LI } & \multicolumn{2}{|c|}{$\begin{array}{l}\text { PS by the } 5 \text { Point- } \\
\text { Likert Scale }\end{array}$} \\
\hline & & $\begin{array}{l}\text { Success } \\
\text { (n) }\end{array}$ & $\begin{array}{c}\text { Failure } \\
\text { (n) }\end{array}$ & p-value & $\begin{array}{c}\text { Cases } \\
\text { (n) }\end{array}$ & $\begin{array}{c}\text { Noncases } \\
\text { (n) }\end{array}$ & p-value & Mean \pm SD & p-value \\
\hline $\begin{array}{l}\text { Subgroups by } \\
\text { amount of } \\
\text { deviation }\end{array}$ & $\begin{array}{l}\text { ET I5 PD } \\
\text { ET } 20 \text { PD } \\
\text { ET } 25 \text { PD }\end{array}$ & $\begin{array}{l}3 \\
3 \\
3\end{array}$ & $\begin{array}{l}0 \\
0 \\
2\end{array}$ & 0.46 & $\begin{array}{l}1 \\
0 \\
0\end{array}$ & $\begin{array}{l}2 \\
3 \\
5\end{array}$ & 0.55 & $\begin{array}{l}4 \pm 1 \\
5 \pm 0 \\
5 \pm 0\end{array}$ & 0.05 \\
\hline $\begin{array}{l}\text { Subgroups by } \\
\text { type of ET }\end{array}$ & $\begin{array}{l}\text { Nonaccommodative ET } \\
\text { Sensory ET }\end{array}$ & $\begin{array}{l}7 \\
2\end{array}$ & $\begin{array}{l}2 \\
0\end{array}$ & 1.00 & $\begin{array}{l}1 \\
0\end{array}$ & $\begin{array}{l}8 \\
2\end{array}$ & 1.00 & $\begin{aligned} 4.67 & \pm 0.71 \\
5 & \pm 0\end{aligned}$ & 0.54 \\
\hline
\end{tabular}

Abbreviations: ET, esotropia; PD, prism diopter; SD, standard deviation; LI, lateral incomitance; PS, patient satisfaction. 
reveal any statistical significance in rate of lateral incomitance, as shown in Tables 4 and 5.

The mean $( \pm \mathrm{SD})$ patient satisfaction scores (PS) assessed by using the 5 point-Likert scale were $4.12 \pm$ 0.97 and $4.73 \pm 0.65$ in XT and ET patients, respectively $(\mathrm{p}=0.07)$. Patients with successful alignment had PS results of $4.46 \pm 0.74$, which is greater than PS from patients without $(3.75 \pm 0.35)$. However, the difference was not statistically significant $(\mathrm{P}=0.17)$. PS from patients with lateral incomitance and patients without were similar $(4.22 \pm 1.09$ VS $4.33 \pm 0.88$, p-value $=$ 0.76). PS from each subgroup classified by degree of deviation or type of strabismus were comparable, as displayed in Tables 4 and 5. Other than lateral incomitance, no intraoperative or postoperative adverse events occurred in any of the patients.

Univariate analysis was performed to identify factors affecting surgical success, postoperative lateral incomitance and patient satisfaction. A list of variables included sex, age, follow up time, degree of deviation and type of strabismus. Continuous variables were converted to categorical variables to simplify the data presentation and the analysis. The analysis as presented in Table 6 did not reveal any association with statistical significance; therefore, no subsequent multivariate analysis was performed.

\section{Discussion}

ULR for small-angle exotropia appear frequently in literature with various surgical dosages and surgical outcomes. Previous noncomparative studies concluded that ULR is effective, with success rates ranging from $73 \%$ to $100 \%, 9,10,12,13,15,17,19-23$ whereas one study showed poor surgical outcomes with a success rate of $36 \%$, a $63 \%$ recurrence rate and $1 \%$ overcorrection rate. ${ }^{33}$ Several authors reported that ULR surgical results were acceptable and comparable to bilateral lateral rectus recession (BLR) or URR. ${ }^{16,30-32}$ Conversely, another study comparing ULR with URR revealed more successful alignment with URR for XT 20 PD at 2 years post-surgery; however, one third of URR patients remained overcorrected up to 6 months post-surgery and the overall rate of overcorrection in URR was higher than ULR. ${ }^{34}$ One investigator reported similar outcomes between ULR as the first vs second procedure for XT 15-20 PD. ${ }^{36}$ In our study, all patients were operated by a single surgeon using the same technique with a fixed formula for the surgical dosage and the results were evaluated prospectively. Satisfactory alignment was obtained in $19(76 \%)$ of the patients with 15-25 PD of exodeviation, with a median (IQR) follow-up of 3, 3-3 months. The surgical results appeared comparable among patients with XT 15, 20, and 25 PD who underwent ULR

Table 6 Results of Univariate Analysis to Identify Factors Affecting Outcomes

\begin{tabular}{|c|c|c|c|c|c|c|c|c|c|}
\hline & & \multicolumn{3}{|c|}{ Successful Alignment } & \multicolumn{3}{|c|}{ Postoperative LI } & \multicolumn{2}{|c|}{$\begin{array}{l}\text { PS by the } 5 \text { Point- } \\
\text { Likert Scale }\end{array}$} \\
\hline & & $\begin{array}{c}\text { Success } \\
\text { (n) }\end{array}$ & $\begin{array}{c}\text { Failure } \\
\text { (n) }\end{array}$ & p-value & $\begin{array}{c}\text { Cases } \\
\text { (n) }\end{array}$ & $\begin{array}{c}\text { Noncases } \\
\text { (n) }\end{array}$ & p-value & Mean \pm SD & p-value \\
\hline Sex & $\begin{array}{l}\text { Female } \\
\text { Male }\end{array}$ & $\begin{array}{c}25 \\
3\end{array}$ & $\begin{array}{l}6 \\
2\end{array}$ & 0.31 & $\begin{array}{l}7 \\
2\end{array}$ & $\begin{array}{c}24 \\
3\end{array}$ & 0.58 & $\begin{array}{c}4.41 \pm 0.76 \\
3.6 \pm 1.52\end{array}$ & 0.06 \\
\hline Age & $\begin{array}{l}18-30 \text { years } \\
31-40 \text { years } \\
>40 \text { years }\end{array}$ & $\begin{array}{l}14 \\
7 \\
7\end{array}$ & $\begin{array}{l}4 \\
4 \\
0\end{array}$ & 0.183 & $\begin{array}{l}4 \\
4 \\
1\end{array}$ & $\begin{array}{c}14 \\
7 \\
6\end{array}$ & 0.60 & $\begin{aligned} 4.22 & \pm 0.94 \\
4 & \pm 1 \\
5 & \pm 0\end{aligned}$ & 0.06 \\
\hline Follow up time & $\begin{array}{l}3-6 \text { months } \\
>6 \text { months }\end{array}$ & $\begin{array}{c}23 \\
5\end{array}$ & $\begin{array}{l}7 \\
1\end{array}$ & 1.00 & $\begin{array}{l}8 \\
1\end{array}$ & $\begin{array}{c}22 \\
5\end{array}$ & 1.00 & $\begin{array}{l}4.2 \pm 0.97 \\
4.9 \pm 0.52\end{array}$ & 0.30 \\
\hline $\begin{array}{l}\text { Subgroups by } \\
\text { amount of } \\
\text { deviation }\end{array}$ & $\begin{array}{l}\text { I5 PD } \\
20 \mathrm{PD} \\
25 \mathrm{PD}\end{array}$ & $\begin{array}{c}9 \\
9 \\
10\end{array}$ & $\begin{array}{l}2 \\
2 \\
4\end{array}$ & 0.78 & $\begin{array}{l}3 \\
3 \\
3\end{array}$ & $\begin{array}{l}8 \\
8 \\
11\end{array}$ & 1.00 & $\begin{array}{l}4.27 \pm 1.10 \\
4.27 \pm 0.79 \\
4.35 \pm 0.93\end{array}$ & 0.97 \\
\hline $\begin{array}{l}\text { Subgroups by } \\
\text { type of } \\
\text { strabismus }\end{array}$ & $\begin{array}{l}\text { Constant XT } \\
\text { Intermittent XT } \\
\text { Nonaccommodative ET } \\
\text { Sensory strabismus }\end{array}$ & $\begin{array}{c}4 \\
12 \\
7 \\
5\end{array}$ & $\begin{array}{l}2 \\
3 \\
2 \\
1\end{array}$ & 0.94 & $\begin{array}{l}1 \\
5 \\
1 \\
2\end{array}$ & $\begin{array}{c}5 \\
10 \\
8 \\
4\end{array}$ & 0.68 & $\begin{array}{l}4.5 \pm 0.55 \\
4.06 \pm 0.96 \\
4.67 \pm 0.71 \\
4.16 \pm 1.33\end{array}$ & 0.44 \\
\hline
\end{tabular}

Abbreviations: PD, Prism diopter; XT, Exotropia; ET, Esotropia; SD, STANDARD deviation; LI, Lateral incomitance; PS, Patient satisfaction. 
of 8,9 , and $10 \mathrm{~mm}$, respectively $(\mathrm{p}=0.99)$. The success rate in our study was superior compared to some published data, possibly owing to greater surgical dosage. Each previous published study used different amounts of recession, and in the majority of the studies, the amount was less than in our study. Only one study comparing surgical outcomes following the different degrees of recession revealed that $9 \mathrm{~mm}$ is preferred for XT $20 \mathrm{PD}$, which is the same number as in our study. ${ }^{29}$ Moreover, inconsistent surgical outcomes between studies was likely caused by different inclusion criteria, definition of success, follow-up time, demographic backgrounds, and variable surgeon technique and experience.

One of the major advantages of ULR is the small percentage of overcorrection. Consecutive ET after strabismus surgery may lead to intolerable diplopia and loss of stereopsis, requiring further intervention. Several authors also reported no overcorrection or at least noted overcorrection only in the early postoperative period, which disappeared over time. ${ }^{9,10,12,16,20,21,29-32}$ Consecutive ET following ULR was reported in some studies at a low rate ranging from $1 \%$ to $10 \%$ of the patients. ${ }^{12,15,17,19,22,33,34}$ In our study, we saw no patients with overcorrection in the early postoperative period and in the most recent follow-up examination, which reflects the particular advantage of ULR. We saw minimal difference in alignment from the early postoperative period to the last examination. Several studies reported small degrees of exodrift from the immediate postoperative period to the most recent follow-up examination. ${ }^{10,13,16,21,30,31,34}$ Therefore, significant changes in early versus late alignment should not be expected following ULR.

Lateral incomitance is a possible complication after ULR. This complication was not observed in any patients undergoing ULR in several studies. . $^{10,16,19-21,29,30,33}$ Notably, there was a recommendation that a single lateral rectus should not be recessed more than $9 \mathrm{~mm}$ due to the risk of lateral incomitance, ${ }^{15}$ however, one study revealed no lateral incomitance following ULR of up to $10 \mathrm{~mm} .^{22}$ In some patients undergoing ULR exceeding $9 \mathrm{~mm}$, this complication was noted only in the early postoperative period, which decreased with time, and disappeared 2-4 months after surgery. ${ }^{31,32}$ The low incidence of lateral incomitance after ULR can be explained by the long arc of contact of the lateral rectus muscle and the position of functional equator that is posterior to the anatomical equator. ${ }^{10}$ In our study, postoperative lateral incomitance was observed after ULR at a rate of $32 \%$ in the early postoperative period and at the final examination. Despite the considerable number of patients with lateral incomitance, all incidences of lateral incomitance following ULR constituted mild abduction limitation that remained stable throughout the study period. Although one patient reported diplopia when gazing toward the operated eye in the early postoperative period, the diplopia eventually completely resolved 3 months after surgery. This incomitance was considered functionally and cosmetically acceptable, with the patient scoring $4 / 5$ points on the Likert scale. According to previous evidence and our findings in the present study, postoperative lateral incomitance after ULR was not a major problem and may disappear with time.

Recession of the unilateral medial rectus as a management for small-angle esotropia has been investigated with different surgical dosages ranging from 4 to $8 \mathrm{~mm}$, and resulted in success rates between $63.3 \%$ and $100 \% .{ }^{11,14,17,18,23-28}$ In our study, successful results were achieved in $9(81.81 \%)$ patients with 15-25 PD esodeviation which is consistent with most published studies. ET 25 PD patients who underwent UMR of $7 \mathrm{~mm}$ achieved the lowest rate $(60 \%)$ of successful alignment but the difference was not statistically significant compared to the ET 15 and 20 PD patients $(p=0.46)$. One study assessed the outcomes of unilateral and bilateral medial rectus recession (BMR) and reported that the shifting deviation per millimeter of recession following UMR was substantially smaller than that achieved after BMR. ${ }^{27}$ The authors concluded that the results of UMR were predictable and should be considered using with ET $\leq 25$ PD.

A notable feature of UMR is the low rate of overcorrection. Consecutive XT following UMR was described in some studies at low rates ranging from $0.8 \%$ to $9 \%,{ }^{17,24,27,28}$ while other studies reported no cases. ${ }^{11,14,18,26}$ Late overcorrection was observed at the final examination but not in the early postoperative period in one patient from a total of 49 patients. ${ }^{25}$ In our study, no overcorrection was detected in any of the patients from 2 weeks post operations until the last visit.

It is important to note that UMR for ET has been ongoingly debated. One of the reasons behind this controversy is the concern regarding lateral incomitance. Several studies involving $<7 \mathrm{~mm}$ UMR reported no postoperative lateral incomitance, ${ }^{25,26,28}$ while a large (7$8 \mathrm{~mm}$ ) UMR resulted in some adduction limitation; however, this was not considered clinically significant. ${ }^{24}$ One investigator reported lateral incomitance following $5 \mathrm{~mm}$ UMR in 2 of 10 patients with ET $15-28$ PD. ${ }^{18}$ In our study, 1 of 11 UMR patients showed lateral incomitance 
that disappeared 3 months after surgery. This patient underwent $5.5 \mathrm{~mm}$ UMR, while other patients undergoing $\geq 5.5 \mathrm{~mm}$ of recession did not develop lateral incomitance.

One-muscle instead of two muscle procedures have the benefit of shorter operative and anesthesia times, less incisional scarring, more preserved anterior segment circulation due to less interference to the anterior ciliary artery within the rectus muscles and lower surgical complications, such as bleeding, globe perforation, retinal detachment, and endophthalmitis. Our study revealed the effectiveness of this procedure for both 15-25 PD of XT and ET without overcorrection. Although some patients were undercorrected, further intervention can be performed on more untouched muscles compared with twomuscle surgery. In fact, one muscle recession yielded high patient satisfaction in terms of cosmetic and functional aspects of the eyes after surgery. The dosage of one muscle recession in this study is equal to or slightly less than the summation of total recession from the standard formula for bilateral recession. For example, for a patient with XT 15 $\mathrm{PD}$, the proposed dosage for ULR is $8 \mathrm{~mm}$ and the standard formula dosage for BLR is $4 \mathrm{~mm}$, therefore the amount of ULR from the proposed dosage $(8 \mathrm{~mm})$ is equal to the summation of BLR ( $8 \mathrm{~mm}$ from $4 \mathrm{~mm}$ right lateral rectus recession and $4 \mathrm{~mm}$ left lateral rectus recession) from the standard formula. As another example, the proposed dosage for ULR is $9 \mathrm{~mm}$ and the standard formula dosage for BLR is $5 \mathrm{~mm}$ for a patient with XT 20 $\mathrm{PD}$, therefore the amount of ULR from the proposed dosage is slightly less than total recession $(10 \mathrm{~mm}$ from $5 \mathrm{~mm}$ right lateral rectus recession and $5 \mathrm{~mm}$ left lateral rectus recession) from the standard formula for BLR. Due to the dosage of one muscle recession being equal to or less than the total bilateral recession amount, the dosage of one muscle recession in this study might theoretically result in less deviation correction compared to bilateral recession from the standard formula. The surgical dosage of unilateral recession and URR could not be directly compared because the procedures are dissimilar. In XT patents, some studies reported comparable surgical results between ULR and BLR or URR, ${ }^{16,30-32}$ while one study shown superior successful outcome at 2 years in URR compared to ULR in XT $20 \mathrm{PD}^{34}$ Another disadvantage of unilateral muscle surgery, including unilateral recession and URR, is the risk of postoperative lateral incomitance while bilateral recession is unlikely to do so. In comparative studies between ULR and URR, one study showed $2.4 \%$ of ULR patients having lateral incomitance 1 month after surgery which resolved by the $2^{\text {nd }}$ month and none of URR patients had postoperative lateral incomitance. ${ }^{31}$ Another study reported abduction limitation rate of $16.2 \%$ in ULR group and $3 \%$ in URR group at one month; however, no abduction limitation from either procedure persisted through 4 months. ${ }^{32}$ Several studies reported no lateral incomitance follow one muscle recession. ${ }^{10,16,19-22,25,26,28-30,33}$ The non-significance of lateral incomitance after one-muscle recession has been confirmed in previous articles ${ }^{18,24,31,32}$ and in our study. The comparable patient satisfaction scores between patients with postoperative lateral incomitance and patients without indicated that this complication might not be troublesome for patients. From the above discussion, we suggest that the advantages outweigh drawbacks, hence one-muscle recession can be used as a primary intervention for small-angle horizontal strabismus. Nevertheless, surgeons' experience and preference play an important role in the decision to perform one-muscle recession since it is dependent on the procedure best suited for their practice.

The main strengths of this study are its prospective design and that all operations were performed by a single surgeon using the same method. The surgical dosage in this study was derived from the commonly used surgical number for strabismus surgery using a simple formula; therefore, this guideline is practical. Limitations in this study include relatively short follow up periods especially in ULR for XT which may have high long term recurrence rate, ${ }^{33}$ small number of patients, and noncomparative study design. Future studies with larger sample sizes, longer follow-up times, and a comparison group are needed to emphasize the efficacy of our proposed recession amount used for one-muscle recession for 15-25 PD horizontal comitant strabismus.

\section{Conclusions}

One-muscle recession with a specific surgical dosage, as described in this article, is effective in managing patients with small-angle XT or ET. We observed a considerable rate of nonsignificant postoperative lateral incomitance following both ULR and UMR. Cosmetic and functional outcomes were satisfactory, according to the patients' subjective grading. This procedure is safe and should be considered as a primary treatment for horizontal deviation of $\leq 25$ PD. 


\section{Abbreviations}

XT, Exotropia; ET, Esotropia; URR, Combined unilateral rectus recession and antagonist rectus resection; PD, Prism diopters; ULR, Unilateral lateral rectus recession; UMR, Unilateral medial rectus recession; VA, Visual acuity; SD, Standard deviation; IQR, Interquartile range; BLR, Bilateral lateral rectus recession; BMR, Bilateral medial rectus recession.

\section{Data Sharing Statement}

For questions regarding data availability, please contact the corresponding author.

\section{Funding}

The patients' compensation for time and inconvenience and orthoptic instruments were supported by the Faculty of Medicine, Ramathibodi Hospital, Mahidol University and by the Eye Foundation of Thailand. These sponsors had no role in study design, data collection, data analysis, or writing the manuscript.

\section{Disclosure}

The authors report no conflicts of interest related to this work. $=99$ )

\section{References}

1. Hashemi H, Pakzad R, Heydarian S, et al. Global and regional prevalence of strabismus: a comprehensive systematic review and meta-analysis. Strabismus. 2019;27(2):54-65.

2. Fiess A, Elflein HM, Urschitz MS, et al. Prevalence of strabismus and its impact on vision-related quality of life: results from the German population-based Gutenberg Health Study. Ophthalmology 2020;127(8):1113-1122.

3. Durnian JM, Owen ME, Marsh IB. The psychosocial aspects of strabismus: correlation between the AS-20 and DAS59 quality-oflife questionnaires. $J$ AAPOS. 2009;13(5):477-480.

4. Menon V, Saha J, Tandon R, Mehta M, Khokhar S. Study of the psychosocial aspects of strabismus. $J$ Pediatr Ophthalmol Strabismus. 2002;39(4):203-208.

5. Mojon-Azzi SM, Kunz A, Mojon DS. Strabismus and discrimination in children: are children with strabismus invited to fewer birthday parties? Br J Ophthalmol. 2011;95(4):473-476.

6. Nelson BA, Gunton KB, Lasker JN, Nelson LB, Drohan LA. The psychosocial aspects of strabismus in teenagers and adults and the impact of surgical correction. J AAPOS. 2008;12(1):72.e71-76.e71.

7. Ribeiro G, de B, Bach AG, Faria CM, Anastasia S, Almeida HC Quality of life of patients with strabismus. Arq Bras Oftalmol. 2014;77(2):110-113.

8. Satterfield D, Keltner JL, Morrison TL. Psychosocial aspects of strabismus study. Arch Ophthalmol. 1993;111(8):1100-1105.

9. Deutsch JA, Nelson LB, Sheppard RW, Burke MJ. Unilateral lateral rectus recession for the treatment of exotropia. Ann Ophthalmol. 1992;24(3):111-113.=99)
10. Kamlesh DS. Long-term results of unilateral lateral rectus recession in intermittent exotropia. J Pediatr Ophthalmol Strabismus. 2003;40 (5):283-287.

11. Zak TA. Results of large single medial rectus recession. $J$ Pediatr Ophthalmol Strabismus. 1986;23(1):17-21.

12. Nelson LB, Bacal DA, Burke MJ. An alternative approach to the surgical management of exotropia-the unilateral lateral rectus recession. J Pediatr Ophthalmol Strabismus. 1992;29(6):357-360.

13. Olitsky SE. Early and late postoperative alignment following unilateral lateral rectus recession for intermittent exotropia. $J$ Pediatr Ophthalmol Strabismus. 1998;35(3):146-148.

14. Procianoy E, Justo DM. Results of unilateral medial rectus recession in high AC/A ratio esotropia. J Pediatr Ophthalmol Strabismus. 1991;28(4):212-214.

15. Weakley DR Jr, Stager DR. Unilateral lateral rectus recessions in exotropia. Ophthalmic Surg. 1993;24(7):458-460.

16. Menon V, Singla MA, Saxena R, Phulijele S. Comparative study of unilateral and bilateral surgery in moderate exotropia. J Pediatr Ophthalmol Strabismus. 2010;47(5):288-291.

17. Hopker LM, Weakley DR. Surgical results after one-muscle recession for correction of horizontal sensory strabismus in children. $J$ AAPOS. 2013;17(2):174-176

18. Pollard ZF, Manley D. Unilateral medial rectus recession for small-angle esotropia. Arch Ophthalmol. 1976;94(5):780-781.

19. Spierer O, Spierer A. Unilateral lateral rectus recession is an effective surgery for intermittent exotropia in young children. $B M C$ Ophthalmol. 2021;21(1):10.

20. Lyu IJ, Park KA, Oh SY. Long-term surgical outcomes and factors for recurrence after unilateral lateral rectus muscle recession. $\mathrm{Br}$ J Ophthalmol. 2016;100(10):1433-1436.

21. Spierer A, Ben-Simon GJ. Unilateral and bilateral lateral rectus recession in exotropia. Ophthalmic Surg Lasers Imaging. 2005;36 (2):114-117.

22. Wang L, Nelson LB. Outcome study of unilateral lateral rectus recession for small to moderate angle intermittent exotropia in children. J Pediatr Ophthalmol Strabismus. 2010;47(4):242-247.

23. Almahmoudi FH, Al Shamrani M, Khan AM. The use of one muscle recession for horizontal strabismus. Saudi J Ophthalmol. 2018;32 (3):200-203.

24. Cogen MS, Roberts BW. Graded unilateral supramaximal medial rectus recession for moderate angle esotropia. Binocul Vis Strabismus Q. 2006;21(3):147-153.

25. Wang L, Wang X. Comparison between graded unilateral and bilateral medial rectus recession for esotropia. Br J Ophthalmol. 2012;96 (4):540-543.

26. Grin TR, Nelson LB. Large unilateral medial rectus recession for the treatment of esotropia. $B r \quad J \quad$ Ophthalmol. 1987;71 (5):377-379.

27. Stack RR, Burley CD, Bedggood A, Elder MJ. Unilateral versus bilateral medial rectus recession. J AAPOS. 2003;7(4):263-267.

28. Wang L, Nelson LB. Outcome study of graded unilateral medial rectus recession for small to moderate angle esotropia. $J$ Pediatr Ophthalmol Strabismus. 2011;48(1):20-24.

29. Oh SY, Choi HY, Lee JY, Oh SY. Surgical outcomes related to degree of unilateral lateral rectus muscle recession in intermittent exotropia of 20 prism diopters. Jpn J Ophthalmol. 2020;64(6):621-627.

30. Spierer O, Spierer A, Glovinsky J, Ben-Simon GJ. Moderateangle exotropia: a comparison of unilateral and bilateral rectus muscle recession. Ophthalmic Surg Lasers Imaging. 2010;41 (3):355-359.

31. Kim HJ, Kim D, Choi DG. Long-term outcomes of unilateral lateral rectus recession versus recess-resect for intermittent exotropia of 20-25 prism diopters. BMC Ophthalmol. 2014;14:46.

32. Suh SY, Choi J, Kim SJ. Comparative study of lateral rectus recession versus recession-resection in unilateral surgery for intermittent exotropia. J AAPOS. 2015;19(6):507-511. 
33. Yang HK, Kim MJ, Hwang JM. Predictive factors affecting long-term outcome of unilateral lateral rectus recession. PLoS One. 2015;10(9): e0137687.

34. Kim H, Yang HK, Hwang JM. Comparison of long-term surgical outcomes between unilateral recession and unilateral recession-resection in small-angle exotropia. Am J Ophthalmol. 2016;166:141-148.
35. Burian HM. Exodeviations: their classification, diagnosis and treatment. Am J Ophthalmol. 1966;62(6):1161-1166.

36. Lee K, Shin KS, Kim Y, Choi MY. Comparison of outcomes of unilateral lateral rectus recession for exotropia between first and second operations. Korean J Ophthalmol. 2011;25(5):329-333.

\section{Publish your work in this journal}

Clinical Ophthalmology is an international, peer-reviewed journal covering all subspecialties within ophthalmology. Key topics include: Optometry; Visual science; Pharmacology and drug therapy in eye diseases; Basic Sciences; Primary and Secondary eye care; Patient Safety and Quality of Care Improvements. This journal is indexed on PubMed

Submit your manuscript here: https://www.dovepress.com/clinical-ophthalmology-journal
Central and CAS, and is the official journal of The Society of Clinical Ophthalmology (SCO). The manuscript management system is completely online and includes a very quick and fair peer-review system, which is all easy to use. Visit http://www.dovepress.com/ testimonials.php to read real quotes from published authors. 